\title{
Preparation of High Specific Surface Area Activated Carbon from Black Wolfberry Branches as an Efficient Electrode Material for Supercapacitors
}

Gaofeng Shi*, Qi Zhang, Chao Liu, Guoying Wang, YucanDong, Zhao Wang, Hongquan Zhang, PengZhang, Fenfang Luo, Xin Li

School of Petrochemical Engineering, Lanzhou University of Technology, NO.287, Lan gong ping Road, Lanzhou, Gansu, China

*E-mail: gaofengshi 1zh@163.com

doi: $10.20964 / 2019.08 .95$

Received: 7 April 2019 / Accepted: 11 June 2019 / Published: 30 June 2019

Black wolfberry branches are used as raw materials, and the $\mathrm{KOH}$ activation method is adopted for producing activated carbons with a high specific surface area. The characterization of the material reveals that with increasing activation temperatures, the specific surface area (SSA) and interconnected microporous/mesoporous structure are augmented. The SSA of the prepared material reaches $2046.07 \mathrm{~m}^{2} \mathrm{~g}^{-1}$ and a high pore volume of $0.7 \mathrm{~cm}^{3} \mathrm{~g}^{-1}$ is obtained. Furthermore, the prepared material exhibits excellent electrical performance. As an electrode material, the specific capacitance is as high as $355.7 \mathrm{~F} \mathrm{~g}^{-1}$. at a current density of $1 \mathrm{~A} \mathrm{~g} \mathrm{~g}^{-1}$, and the capacitance loss rate is $6.4 \%$ after 5000 cycles of charging and discharging at a current density of $2 \mathrm{~A} \mathrm{~g}^{-1}$. These findings indicate that the wolfberry branch is a kind of biomass material, especially suitable for the preparation of super-activated carbon.

Keywords: Black wolfberry branches; supercapacitors; electrode materials; electrochemical performance

\section{FULL TEXT}

(C) 2019 The Authors. Published by ESG (www.electrochemsci.org). This article is an open access article distributed under the terms and conditions of the Creative Commons Attribution license (http://creativecommons.org/licenses/by/4.0/). 